\title{
Case Report \\ Self-Expandable Metal Stenting of Refractory Upper Gut Corrosive Strictures: A New Role for Endoscopy?
}

\author{
Raffaele Manta, ${ }^{1}$ Rita Conigliaro, ${ }^{1}$ Helga Bertani, ${ }^{1}$ Mauro Manno, ${ }^{1}$ Ahmed Soliman, ${ }^{1}$ \\ Paolo Fedeli, ${ }^{2}$ and Gabrio Bassotti ${ }^{3}$ \\ ${ }^{1}$ Gastroenterology and Endoscopy Unit, S. Agostino Estense Civil Hospital, Baggiovara Modena, Italy \\ ${ }^{2}$ Gastroenterology Unit, Santo Spirito Hospital, Rome, Italy \\ ${ }^{3}$ Gastroenterology \& Hepatology Section, Department of Clinical \& Experimental Medicine, Perugia Medical University School, Italy
}

Correspondence should be addressed to Raffaele Manta, r.manta@ausl.mo.it

Received 26 May 2011; Accepted 15 June 2011

Academic Editors: T. Hirata and A. J. Lembo

Copyright (c) 2011 Raffaele Manta et al. This is an open access article distributed under the Creative Commons Attribution License, which permits unrestricted use, distribution, and reproduction in any medium, provided the original work is properly cited.

Caustic strictures of the gastrointestinal tract are often difficult to treat, since relapses are frequent after medical or endoscopic treatment. Thus, novel approaches are needed. We report here our experience with self-expandable metallic stents (SEMS) as a new endoscopic approach in three patients with corrosive strictures of the upper gastrointestinal tract.

\section{Introduction}

Caustic injury to the upper gastrointestinal (GI) tract represents a significant medical and social problem [1]. In pediatric patients, caustic ingestion is usually accidental [2], whereas in adults, it is more often intentional, associated with suicide attempts, and usually involves strong acids $[3,4]$.

Although mortality is not high, there is a highly related morbidity rate: caustic ingestion may thus cause perforations and necrosis in the acute phase, while the late complications include stricture formation, especially in the esophagus and the antrum, and the development of esophageal and, rarely, gastric carcinoma $[5,6]$.

Endoscopic management of caustic strictures of the esophagus and the gastric antrum usually relies on dilatation procedures [7-9], although alternative procedures may be used as a first therapeutic choice or when dilatation is not effective $[10,11]$.

In recent years, the use of endoscopic stenting for nonneoplastic stenoses has been implemented, in both pediatric and adult subjects [12-15].

We report three cases of corrosive injury of the upper GI tract treated by self-expandable metal stents (SEMS) positioning.

\section{Case Series}

2.1. Patient 1. A 50-year old woman with bipolar manicdepressive syndrome was referred to our Endoscopy Unit after voluntary ingestion of an unidentified volume and concentration of muriatic acid. On admission, her main complaint was chest pain; physical examination was normal. Chest and abdomen X-ray films did not reveal any abnormalities, and water soluble CT scan did not show perforation. Upper endoscopy performed in the first 24 hours after ingestion showed multiple ulcers with extensive necrosis of esophagus and stomach, while the duodenum was edematous with some erosions and superficial ulcerations (stage $3 \mathrm{~B}$ and $2 \mathrm{~A}$, resp., according to the classification of Zargar and colleagues [16], Table 1). A central venous catheter was inserted for nutritional support, and the patient was treated with antibiotics and omeprazole, $40 \mathrm{mg}$ bid, i.v. The patient was discharged one week later on oral omeprazole therapy. After a month, she was admitted again due to vomiting. Upper GI endoscopy, performed by a pediatric instrument (Pentax EG-2930K), revealed two substenotic tracts of the esophagus 15 and $35 \mathrm{~cm}$ from the incisors. Fragility of gastric mucosa and a $7 \mathrm{~cm}$ antropyloric stricture were also observed. An upper GI series revealed a decreased calibre 


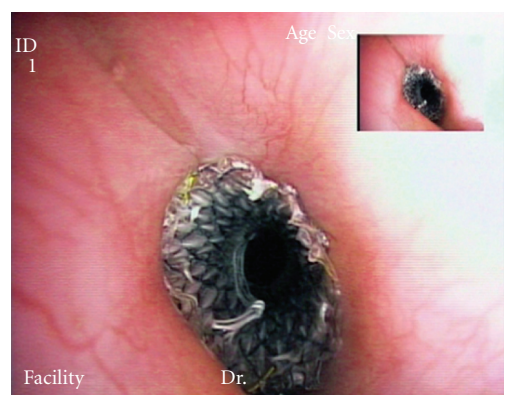

(a)

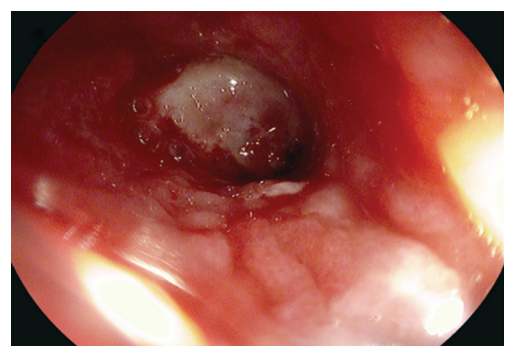

(c)

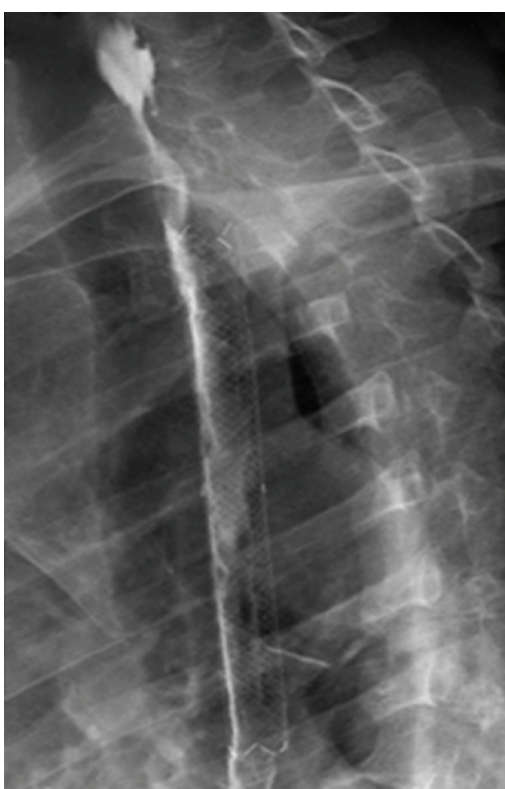

(b)

Figure 1: (a) Conio stent placed across the cervical stenosis. (b) Radiologic control of stent positioning by water soluble contrast medium. (c) Cervical esophageal lumen after stent removal: beyond the stenotic tract a decubitus ulcer is seen.

of the distal esophagus, the distal part of the antrum, and pylorus. Pneumatic balloon dilation (CRE Boston Scientific diameter $12-15 \mathrm{~mm}$, at 6 ATM) of the antropyloric stenosis was carried out and repeated (balloon diameter $18-20 \mathrm{~mm}$, 4-6 ATM) after a month for recurrence of a $5 \mathrm{~cm}$ stenosis. At one-month followup, the stenosis was still present and was retreated by balloon dilatation (diameter $12-15 \mathrm{~mm}$ at 6 ATM) followed by SEMS positioning (Taewoong pyloric covered metallic stent, $18 \times 60 \mathrm{~mm})$. After three months, when planned SEMS extraction, the patient complained of dysphagia. Endoscopy showed a cervical stricture and a double stricture of the medium esophagus $(22$ and $30 \mathrm{~cm}$ from incisors, resp.), the latter successfully treated in one session by Savary dilators ( 9 to $16 \mathrm{~mm}$ ) under fluoroscopic guidance, followed by intralesional corticosteroids injection (triamcinolone acetonide $40 \mathrm{mg} / 10 \mathrm{~mL}$ ). The cervical stricture was treated in five endoscopic sessions by balloon dilation (diameter up to $18 \mathrm{~mm}, 4,5 \mathrm{ATM}$ ) and thereafter by SEMS (Taewoong Conio-type stent: $16 \mathrm{~mm}, 12 \mathrm{~cm}$ ) placement because of the stricture recurrence (Figures 1(a) and 1(b)). The stent dislodged distally after 2 days and was removed endoscopically on the 3rd day (Figure 1(c)). Restenosis did not occur after stent dislocation. Three months later the pyloric metallic stent was removed after freeing it with argon plasma coagulation (APC). At 24month followup no stricture recurrence was observed.

2.2. Patient 2. A 56-year old schizophrenic woman was referred to our Endoscopy Unit with a diagnosis of pyloric stenosis due to voluntary ingestion of about $500 \mathrm{~mL}$ of caustic substance (benzalconium chloride and muriatic acid in an unknown concentration). Esophagogram with water soluble contrast did not show perforation of the viscus. Upper GI
TABLE 1: Zargar endoscopic classification for caustic mucosal injury (adapted from [7]).

\begin{tabular}{ll}
\hline Grade & Definition \\
\hline 0 & normal findings at endoscopy \\
1 & $\begin{array}{l}\text { edema and hyperemia of mucosa } \\
\text { friability, hemorrages, erosions, blisters, whitish } \\
\text { membranes, exudates and superficial ulcerations } \\
\text { 2A }\end{array}$ \\
grade 2A plus deep discrete or circumferential \\
ulcerations \\
small scattered multiple ulcerations and areas of \\
necrosis (brown-black or greyish discoloration) \\
3B & extensive necrosis \\
\hline
\end{tabular}

endoscopy showed hyperemia and edema of the prepyloric and pyloric mucosa with narrowed but passable pylorus by a standard endoscope. The mucosal injury was classified as grade 1 according to the above classification. Total parenteral nutrition (TPN) was started together with i.v. omeprazole, $40 \mathrm{mg}$ bid. At one-month followup, endoscopy showed pyloric stricture. An upper GI series showed a $4 \mathrm{~cm}$ long prepyloric stenosis. Pneumatic dilatation using CRE balloon (Boston Scientific, diameter $12-15$ at 6 ATM) was performed in three consecutive sessions, and a covered SEMS (Taewoong Pyloric $18 \mathrm{~mm}, 6 \mathrm{~cm}$ ) was placed under fluoroscopic guidance for stricture recurrence. The patient was discharged after two days, and omeprazole, $20 \mathrm{mg}$ bid, was prescribed. Three months later the SEMS was removed after cutting and freeing with a clamp tissue overgrowth at the edges of the metallic mesh. Subsequent endoscopy and upper GI series revealed resolution of the stenosis. After three months, endoscopic followup showed a substenosis of the 
pyloric tract that was retreated by balloon dilation (up to $18 \mathrm{~mm}$ diameter at $4.5 \mathrm{ATM}$ ). The patient was asymptomatic after 6 months of followup.

2.3. Patient 3. A 38-year old man was admitted at our Endoscopy Unit after voluntary ingestion of an unidentified volume and concentration of muriatic acid. A CT scan with water soluble contrast did not show esophageal perforation. Upper GI endoscopy showed hyperemia, edema, and friability associated to erosions of the cervical esophagus and extensive necrosis of the stomach. The duodenal bulb was very edematous with multiple erosions and superficial ulcerations (stages 2A and 3B, resp., according to the above classification). TPN was started together with i.v. omeprazole, $40 \mathrm{mg}$ bid, and antibiotic therapy. After 20 days, GI endoscopy showed a double stenosis of cervical esophagus and a pyloric stricture impassable with a paediatric instrument. An upper GI series showed a $5.5 \mathrm{~cm}$ long prepyloric stenosis. Mechanic dilatation (Savary) up to $16 \mathrm{~mm}$ diameter followed by pneumatic dilatation with CRE balloon (Boston Scientific, $12-15 \mathrm{~mm}$ diameter at 4 and 6 ATM) was performed, respectively, for esophageal and pyloric strictures in two consecutive sessions. Thereafter, a covered SEMS (Taewoong Pyloric $20 \mathrm{~mm}, 8 \mathrm{~cm}$ length) was positioned in the antrum under fluoroscopic guidance, while the esophageal stenosis was resolved. The patient was discharged after one week with omeprazole therapy, $20 \mathrm{mg}$ bid. Two months later an endoscopic control showed that the SEMS was almost free in the gastric cavity, and it was extracted. Subsequently, an upper GI series revealed resolution of the stenosis. After three months endoscopy showed narrowing of the pyloric channel, well passable with a standard endoscope (Pentax G-3030K). The patient was asymptomatic after 6 months of followup.

\section{Discussion}

Corrosive agents are acid or alkaline compounds, with a $\mathrm{pH}$ less than 2 or greater than 12 [6]. Alkali ingestion causes more commonly esophageal injuries, whereas the damage caused by acids is maximal in the stomach, and the esophagus is minimally affected $[6,17-19]$. Both alkali and acids penetrate tissues extremely rapidly and cause full thickness damage to the gastrointestinal wall $[6,20,21]$. The extent and severity of caustic injury depends on the $\mathrm{pH}$ of the corrosive agent, its quantity and concentration, the physical state of the caustic substance, the duration of exposure, and the subsequent secondary infection [22].

Mucosal damage can occur up to 7 days after initial injury, and then bacterial invasion, inflammatory response, and development of granulation tissue ensue [23]. Scar retraction begins in the third week and continues for several months thereafter, leading to stricture and shortening of the damaged segment $[24,25]$.

The initial assessment usually starts with a plain lateral neck and chest radiographs, to exclude perforation; in the absence of perforation, endoscopy is the diagnostic procedure of choice $[19,26]$. Endoscopy should be performed not prior than 6 hours (preferably within 12 hours) after caustic ingestion, due to the high risk of iatrogenic damage, and avoided 5 to 15 days after the ingestion, due to wound softening during this period $[16,17,23]$. Identification of the initial damage severity is of paramount importance for management and prognosis, since it allows to distinguish patients with no evidence of GI injury, that can be discharged, from patients with severe injuries [17].

After ingestion of corrosive substances, $38 \%$ to $45 \%$ of patients develop esophageal strictures; gastric outlet obstruction is relatively uncommon, and it is usually found in association with esophageal strictures (20\% of cases) $[17,27]$.

Concerning management, although many treatment modalities have been suggested to prevent the development of such complications, none has yielded univocal success [28-31].

Periodic endoscopic dilation with bougies or balloons in alternative to surgery is the traditional treatment for gastrointestinal stenosis due to corrosive agents [32]. Although the success rate for esophageal strictures may be initially high as to up $85 \%$ [33], following endoscopic dilations, the chance of relapse is high and repeated procedures are often required. Endoscopic dilations results are also good in the short-term period for gastric strictures, but the midand long-term therapeutic efficacy is often unsatisfactory [34]. The therapeutic success depends on both number and frequency of dilation, balloon pressure, and the anatomy of the strictures; although it has been suggested a step-up dilation approach carried out every 2 weeks [35], it must be taken into account the fact that dilations can increase the fibrotic activity of the second phase of wound healing. Thus, intralesional corticosteroid therapy has been added to dilations, showing beneficial effect for refractory strictures due corrosive agents [36-40].

Over the last decade endoscopic stent insertion has been proposed as an alternative treatment to repeated dilations for refractory benign esophageal stricture, prior to surgery.

Thus, the self-expandable plastic (SEPSs) and metallic (SEMSs) stents have been used successfully as treatment of benign strictures of the GI tract $[14,34,41]$. The use of SEPS presents some advantages over SEMS, such as the absence of a metal mesh and the completely covering silicone membrane, that reduce mucosal overgrowth at the stent edges and allow safe removal, even though the stent has been in place for few months. Furthermore SEPSs, by a wider surface and an higher expansive force, reduce the risk of dislocation [41-43]; the limit of SEPS is that it is possible to place them only into esophageal strictures.

SEMSs are commonly used for palliative treatment of patients with malignant dysphagia, and have dramatically reduced the morbidity of esophageal stent insertion compared with that associated to the placement of rigid plastic stents [44]. Also, SEMSs have been successfully used for palliative treatment of malignant gastric outlet obstruction [45].

SEMSs have never been proposed for benign caustic strictures of pyloric region, as this kind of strictures is 
relatively uncommon and also because the covered (totally or partially) metal enteral stents have been available just recently. The choice between totally or partially covered stent is secondary to the stricture morphology and the probability of stent dislocation, depending on how much the tract is narrow and straight.

Here we report our experience with SEMS for the treatment of caustic upper GI strictures. We used SEMS since we have a good experience (109 metallic stents positioned in the last 5 years, with 12 of these procedures carried out in patients with benign GI tract diseases. In these patients SEMS were left in place for periods of 1-3 months, with good results) in temporary SEMS placement for treatment of esophageal, gastrojejunal anastomotic, and peptic pyloric strictures.

The main problem for temporary metallic stent is to determine the optimal placement period. Caustic strictures are usually difficult to treat because the granulation tissue is very strong and plentiful; therefore, the longer the stent is left in place, the more difficult is to remove it [46]. In our experience, we observed that, later than 4 weeks from stent placement, granulation tissue grows within the distal noncovered areas of the stent and within the stent covered trunk, as a consequence of the silicon cover usury. Moreover, we realized that it is impossible to remove stents without the use of APC in a procedure that is surely time consuming (about 60-90 minutes).

Endoscopy is the first therapeutic approach of caustic stenosis with either step-up mechanical or pneumatic dilations; moreover, the placement of endoscopic stents, that may be subsequently removed, has been established as an effective way to treat benign refractory strictures due to corrosive agents [47, 48]. In our cases SEMS positioning was effective, probably due to the stent radial expansive force exerted, and in selected cases, it might represent a new alternative treatment for patients with caustic esophagogastric strictures. Transient placement of a SEMS could significantly improve prognosis of patients with benign stenoses refractory to dilation procedure. By the use of APC, SEMS can be removed after a long period despite the development of tissue overgrowth at the edges of the stent. This procedure must be performed by skilled hands in referral endoscopic centers. Further studies, also with the new biodegradable stents, are needed in order to confirm the efficacy of this conservative endoscopic technique [49].

\section{Conflict of Interests}

The authors declared that there is no conflict of interests.

\section{References}

[1] S. B. Schaffer and A. F. Hebert, "Caustic ingestion," Journal of the Louisiana State Medical Society, vol. 152, no. 12, pp. 590596, 2000.

[2] F. Riffat and A. Cheng, "Pediatric caustic ingestion: 50 consecutive cases and a review of the literature," Diseases of the Esophagus, vol. 22, no. 1, pp. 89-94, 2009.
[3] V. V. Gumaste and P. B. Dave, "Ingestion of corrosive substances by adults," American Journal of Gastroenterology, vol. 87, no. 1, pp. 1-5, 1992.

[4] K. Ramasamy and V. V. Gumaste, "Corrosive ingestion in adults," Journal of Clinical Gastroenterology, vol. 37, no. 2, pp. 119-124, 2003.

[5] C. E. McAuley, D. L. Steed, and M. W. Webster, "Late sequelae of gastric acid injury," American Journal of Surgery, vol. 149, no. 3, pp. 412-415, 1985.

[6] G. Tekant, E. Eroğlu, E. Erdoǧan et al., "Corrosive injuryinduced gastric outlet obstruction: a changing spectrum of agents and treatment," Journal of Pediatric Surgery, vol. 36, no. 7, pp. 1004-1007, 2001.

[7] M. Atiq, R. E. Kibria, S. Dang et al., "Corrosive injury to the GI tract in adults: a practical approach," Expert Review of Gastroenterology and Hepatology, vol. 3, no. 6, pp. 701-709, 2009.

[8] F. Pace, S. Antinori, and A. Repici, "What is new in esophageal injury (infection, drug-induced, caustic, stricture, perforation)?" Current Opinion in Gastroenterology, vol. 25, no. 4, pp. 372-379, 2009.

[9] M. Lee, "Caustic ingestion and upper digestive tract injury," Digestive Diseases and Sciences, vol. 55, no. 6, pp. 1547-1549, 2010.

[10] V. Gupta, J. D. Wig, R. Kochhar et al., "Surgical management of gastric cicatrisation resulting from corrosive ingestion," International Journal of Surgery, vol. 7, no. 3, pp. 257-261, 2009.

[11] R. Kochhar and K. S. Poornachandra, "Intralesional steroid injection therapy in the management of resistant gastrointestinal strictures," World Journal of Gastrointestinal Endoscopy, vol. 2, pp. 61-68, 2010.

[12] C. Zhang, J. M. Yu, G. P. Fan et al., "The use of a retrievable self-expanding stent in treating childhood benign esophageal strictures," Journal of Pediatric Surgery, vol. 40, no. 3, pp. 501504, 2005.

[13] J. H. Zhou, Y. G. Jiang, R. W. Wang et al., "Management of corrosive esophageal burns in 149 cases," Journal of Thoracic and Cardiovascular Surgery, vol. 130, no. 2, pp. 449-455, 2005.

[14] C. Atabek, I. Surer, S. Demirbag, B. Caliskan, H. Ozturk, and S. Cetinkursun, "Increasing tendency in caustic esophageal burns and long-term polytetrafluorethylene stenting in severe cases: 10 years experience," Journal of Pediatric Surgery, vol. 42, no. 4, pp. 636-640, 2007.

[15] E. Ancona, E. Guido, C. Cutrone et al., "A new endoscopic technique for suspension of esophageal prosthesis for refractory caustic esophageal strictures," Diseases of the Esophagus, vol. 21, no. 3, pp. 262-265, 2008.

[16] S. A. Zargar, R. Kuchhar, S. Mehta et al., "The role of fibroptic endoscopy in the management of corrosive ingestion and modified endoscopic classification of burns," Gastrointestinal Endoscopy, vol. 37, pp. 165-169, 1991.

[17] L. P. Goldman and J. M. Weigert, "Corrosive substance ingestion: a review," American Journal of Gastroenterology, vol. 79, no. 2, pp. 85-90, 1984.

[18] S. A. Zargar, R. Kochhar, B. Nagi, S. Mehta, and S. K. Mehta, "Ingestion of corrosive acids. Spectrum of injury to upper gastrointestinal tract and natural history," Gastroenterology, vol. 97, no. 3, pp. 702-707, 1989.

[19] S. A. Zargar, R. Kochhar, B. Nagi, S. Mehta, and S. K. Mehta, "Ingestion of strong corrosive alkalis: spectrum of injury to 
upper gastrointestinal tract and natural history," American Journal of Gastroenterology, vol. 87, no. 3, pp. 337-341, 1992.

[20] C. Sugawa and C. E. Lucas, "Caustic injury of the upper gastrointestinal tract in adults: a clinical and endoscopic study," Surgery, vol. 106, no. 4, pp. 802-806, 1989.

[21] O. Mutaf, A. Genç, O. Herek, M. Demircan, C. Ozcan, and A. Arikan, "Gastroesophageal reflux: a determinant in the outcome of caustic esophageal burns," Journal of Pediatric Surgery, vol. 31, no. 11, pp. 1494-1495, 1996.

[22] C. Ertekin, O. Alimoglu, H. Akyildiz, R. Guloglu, and K. Taviloglu, "The results of caustic ingestions," HepatoGastroenterology, vol. 51, no. 59, pp. 1397-1400, 2004.

[23] A. F. Hamza, S. Abdelhay, H. Sherif et al., "Caustic esophageal strictures in children: 30 years' experience," Journal of Pediatric Surgery, vol. 38, no. 6, pp. 828-833, 2003.

[24] A. Bautista, R. Varela, A. Villanueva, E. Estevez, R. Tojo, and S. Cadranel, "Motor function of the esophagus after caustic burn," European Journal of Pediatric Surgery, vol. 6, no. 4, pp. 204-207, 1996.

[25] R. C. M. Mamede and F. V. De Mello Filho, "Treatment of caustic ingestion: an analysis of 239 cases," Diseases of the Esophagus, vol. 15, no. 3, pp. 210-213, 2002.

[26] G. Tekant, E. Eroğlu, E. Erdoğan et al., "Corrosive injuryinduced gastric outlet obstruction: a changing spectrum of agents and treatment," Journal of Pediatric Surgery, vol. 36, no. 7, pp. 1004-1007, 2001.

[27] N. Ananthakrishnan, G. Parthasarathy, and V. Kate, "Chronic corrosive injuries of the stomach-a single unit experience of 109 patients over thirty years," World Journal of Surgery, vol. 34, no. 4, pp. 758-764, 2010.

[28] K. D. Anderson, T. M. Rouse, and J. G. Randolph, "A controlled trial of corticosteroids in children with corrosive injury of the esophagus," New England Journal of Medicine, vol. 323, no. 10, pp. 637-640, 1990.

[29] J. M. Howell, W. C. Dalsey, F. W. Hartsell, and C. A. Butzin, "Steroids for the treatment of corrosive esophageal injury: a statistical analysis of past studies," American Journal of Emergency Medicine, vol. 10, no. 5, pp. 421-425, 1992.

[30] M. Bingöl-Koloğlu, F. C. Tanyel, S. Müftüoğlu et al., "The preventive effect of heparin on stricture formation after caustic esophageal burns," Journal of Pediatric Surgery, vol. 34, no. 2, pp. 291-294, 1999.

[31] E. Günel, F. Çağlayan, O. Çağlayan, A. Canbilen, and M. Tosun, "Effect of antioxidant therapy on collagen synthesis in corrosive esophageal burns," Pediatric Surgery International, vol. 18, no. 1, pp. 24-27, 2002.

[32] S. L. Broor, A. Kumar, S. T. Chari et al., "Corrosive oesophageal strictures following acid ingestion: clinical profile and results of endoscopic dilatation," Journal of Gastroenterology and Hepatology, vol. 4, no. 1, pp. 55-61, 1989.

[33] S. Singhal and P. Kar, "Management of acid- and alkaliinduced esophageal strictures in 79 adults by endoscopic dilation: 8-years' experience in New Delhi," Dysphagia, vol. 22, no. 2, pp. 130-134, 2007.

[34] Y. S. Cheng, M. H. Li, W. X. Chen, N. W. Chen, Q. X. Zhuang, and K. Z. Shang, "Comparison of different intervention procedures in benign strictures of gastrointestinal tract," World Journal of Gastroenterology, vol. 10, no. 3, pp. 410-414, 2004.

[35] R. J. Lew and M. L. Kochman, "A review of endoscopic methods of esophageal dilation," Journal of Clinical Gastroenterology, vol. 35, no. 2, pp. 117-126, 2002.
[36] H. J. Mendelson and W. H. Maloney, "The treatment of benign strictures of the esophagus with cortisone injection," Annals of Otology, Rhinology and Laryngology, vol. 79, pp. 900-904, 1970.

[37] G. A. Berenson, R. Wyllie, M. Caulfield, and R. Steffen, "Intralesional steroids in the treatment of refractory strictures," Journal of Pediatric Gastroenterology and Nutrition, vol. 18, no. 2, pp. 250-252, 1994.

[38] M. Lee, C. M. Kubik, C. D. Polhamus, C. E. Brady, and S. C. Kadakia, "Preliminary experience with endoscopic intralesional steroid injection therapy for refractory upper gastrointestinal strictures," Gastrointestinal Endoscopy, vol. 41, no. 6, pp. 598-601, 1995.

[39] R. Kochhar, P. V. J. Sriram, J. D. Ray, S. Kumar, B. Nagi, and K. Singh, "Intralesional steroid injections for corrosive induced pyloric stenosis," Endoscopy, vol. 30, no. 8, pp. 734-736, 1998.

[40] R. Kochhar, J. D. Ray, P. V. J. Sriram, S. Kumar, and K. Singh, "Intralesional steroids augment the effects of endoscopic dilatation in corrosive esophageal stricture," Gastrointestinal Endoscopy, vol. 49, no. 4, pp. 509-513, 1999.

[41] A. Repici, M. Conio, C. De Angelis et al., "Temporary placement of an expandable polyester silicone-covered stent for treatment of refractory benign esophageal strictures," Gastrointestinal Endoscopy, vol. 60, no. 4, pp. 513-519, 2004.

[42] P. Decker, J. Lippler, D. Decker, and A. Hirner, "Use of Polyflex stent in the palliative therapy of esophageal carcinoma: results in 14 cases and review of the literature," Surgical Endoscopy, vol. 15, no. 12, pp. 1444-1447, 2001.

[43] R. Conigliaro, G. Battaglia, A. Repici et al., "Polyflex stents for malignant oesophageal and oesophagogastric stricture: a prospective, multicentric study," European Journal of Gastroenterology and Hepatology, vol. 19, no. 3, pp. 195-203, 2007.

[44] C. A. O'Donnell, G. M. Fullarton, E. Watt, K. Lennon, G. D. Murray, and J. G. Moss, "Randomized clinical trial comparing self-expanding metallic stents with plastic endoprostheses in the palliation of esophageal cancer," British Journal of Surgery, vol. 89, no. 8, pp. 985-992, 2002.

[45] T. Nassif, F. Prat, B. Meduri et al., "Endoscopic palliation of malignant gastric outlet obstruction using self-expandable metallic stents: results of a multicenter study," Endoscopy, vol. 35, no. 6, pp. 483-489, 2003.

[46] W. Cwikiel, R. Willén, H. Stridbeck, R. Lillo-Gil, and C. S. Von Holstein, "Self-expanding stent in the treatment of benign esophageal strictures: experimental study in pigs and presentation of clinical cases," Radiology, vol. 187, no. 3, pp. 667-671, 1993.

[47] K. S. Dua, F. P. Vleggaar, R. Santharam, and P. D. Siersema, "Removable self-expanding plastic esophageal stent as a continuous, non-permanent dilator in treating refractory benign esophageal strictures: a prospective two-center study," American Journal of Gastroenterology, vol. 103, no. 12, pp. 2988-2994, 2008.

[48] T. Thomas, K. R. Abrams, V. Subramanian, J. Mannath, and K. Ragunath, "Esophageal stents for benign refractory strictures: a meta-analysis," Endoscopy, vol. 43, pp. 386-393, 2011.

[49] Y. Saito, T. Tanaka, A. Andoh et al., "Novel biodegradable stents for benign esophageal strictures following endoscopic submucosal dissection," Digestive Diseases and Sciences, vol. 53, no. 2, pp. 330-333, 2008. 


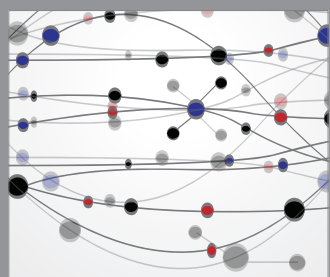

The Scientific World Journal
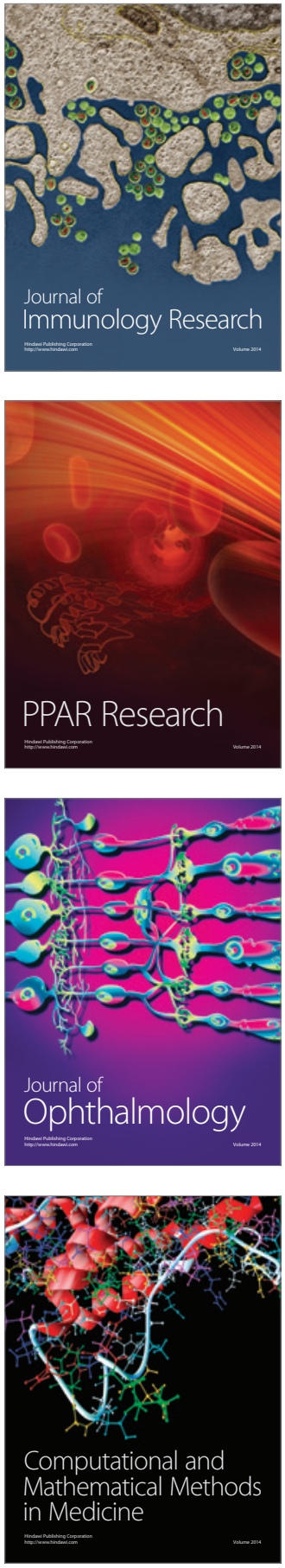

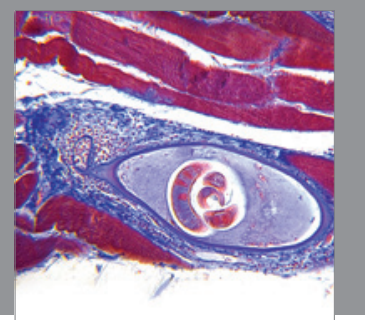

Gastroenterology

Research and Practice
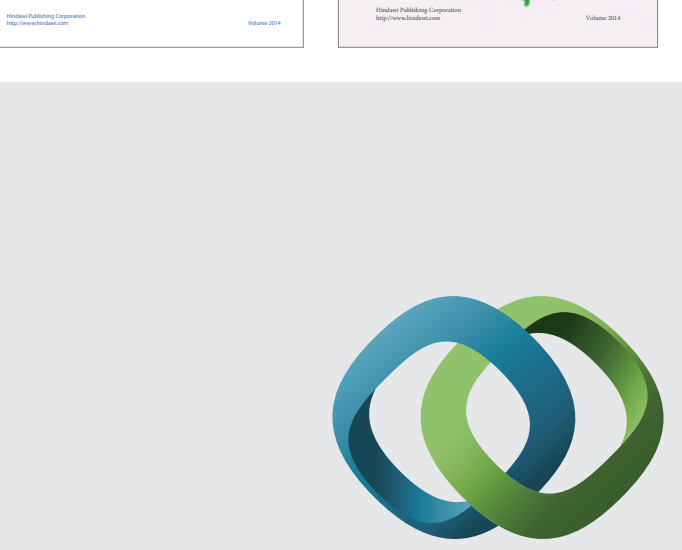

\section{Hindawi}

Submit your manuscripts at

http://www.hindawi.com
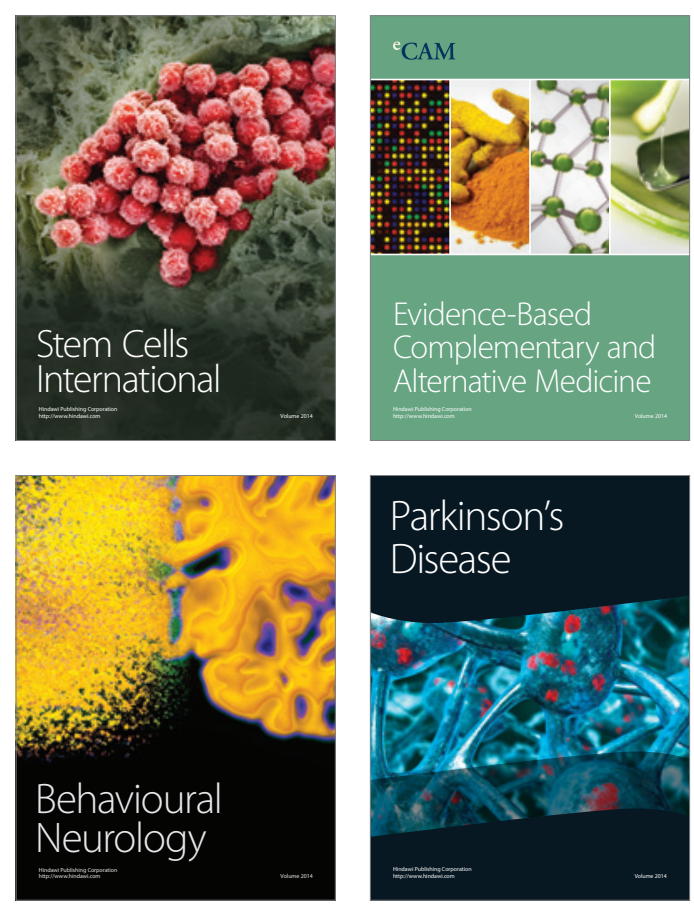

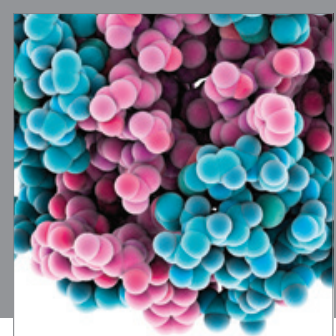

Journal of
Diabetes Research

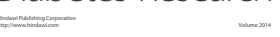

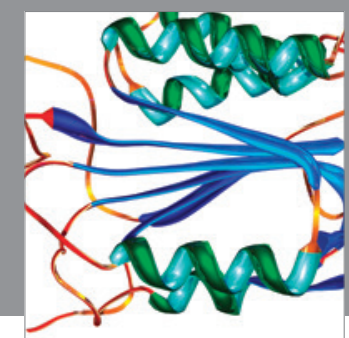

Disease Markers
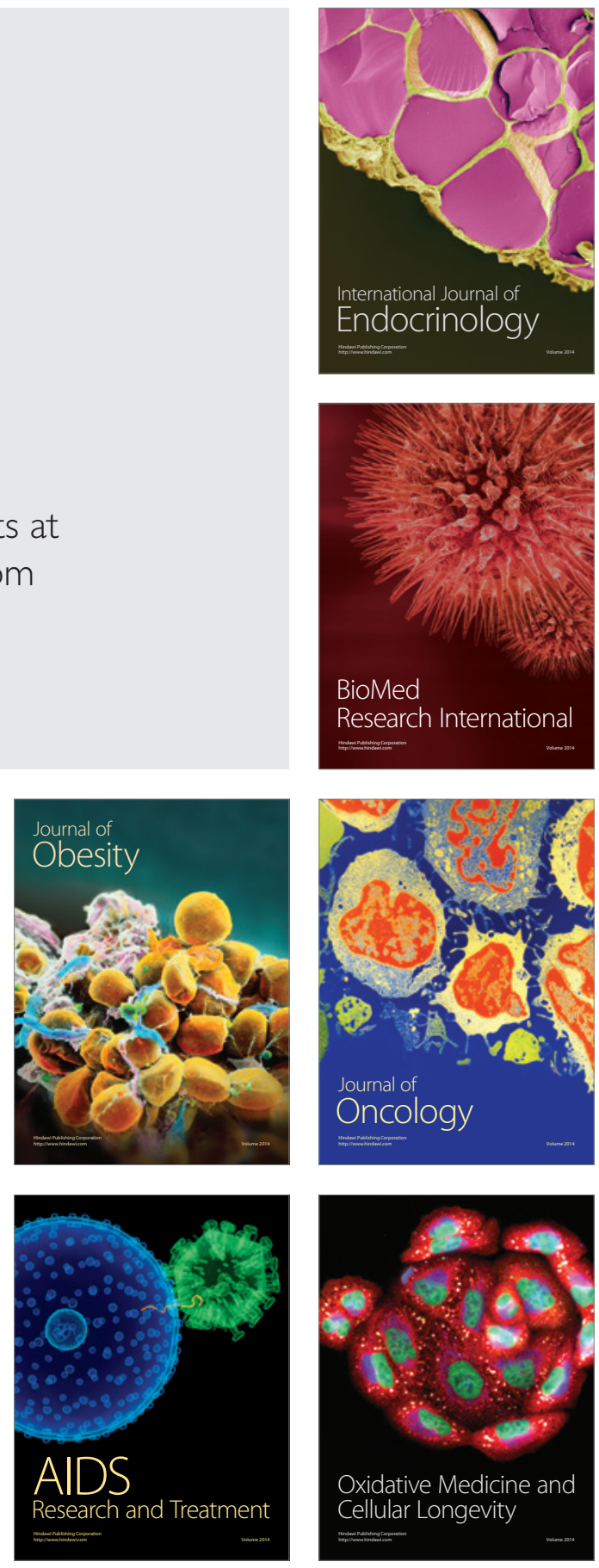